\title{
RAZÕES PARA MUDAR O MUNDO: A EDUCAÇÃO DO CAMPO E A CONTRIBUIÇÃO DO PRONERA
}

\author{
Bernardo Mançano Fernandes ${ }^{1}$ \\ ReBecca TARLAU ${ }^{2}$
}

\begin{abstract}
RESUMO: A razão neoliberal penetra todas as instituições e dissemina sua visão de mundo impondo a governança corporativa em todas as dimensões do desenvolvimento. A educação é uma das dimensóes mais afetadas pela lógica neoliberal. $\mathrm{O}$ campesinato brasileiro, com destaque para o Movimento dos Trabalhadores Rurais Sem Terra (MST), junto com professores e pesquisadores construíram o paradigma da educação do campo que tem no Programa Nacional de Educaçáo na Reforma Agrária (PRONERA) uma de suas principais referências. Neste artigo, analisamos este Programa em escala nacional e discutimos o enfrentamento desses dois paradigmas que disputam as políticas educacionais para o campo. A contribuiçáo do PRONERA, em seus 20 anos de existência, assegura essa política pública como fundamental para a educaçáo camponesa.
\end{abstract}

Palavras-chave: PRONERA. Razão neoliberal. Educação do campo. Debate paradigmático.

\section{REASONS FOR CHANGING THE WORLD: RURAL EDUCATION AND THE CONTRIBUTIONS FROM PRONERA}

ABSTRACT: Neoliberal reasoning permeates all institutions and disseminates its view of the world by imposing corporate governance on all dimensions of development. Education is one of the spheres mostly affected by the neoliberal logic. The Brazilian peasantry, as highlighted by the Landless Workers Movement (MST), along with teachers and researchers, has built an alternative paradigm for rural education through the National Program for Education in Agrarian Reform (PRONERA). In this article, we discuss the confrontation of these two paradigms in dispute within the educational policy field. The contribution of

\footnotetext{
${ }^{1}$ Universidade Estadual Paulista "Júlio de Mesquita Filho", Instituto de Políticas Públicas e Relações Internacionais, Cátedra da Organização das Naçóes Unidas para a Educação, a Ciência e a Cultura (UNESCO) de Educação do Campo e Desenvolvimento Territorial - São Paulo (SP), Brasil. E-mail: bernardo@ippri.unesp.br

${ }^{2}$ Universidade Stanford, Faculdade de Educação - Stanford, Califórnia, Estados Unidos. E-mail: becktar@gmail.com

DOI: 10.1590/ES0101-73302017180679
} 
PRONERA, in twenty years of existence, is to ensure that public policies remain relevant for peasant education.

Keywords: PRONERA. Neoliberal reasoning. Rural education. Paradigmatic debate.

\section{RAISONS POUR CHANGER LE MONDE: L'ÉDUCATION RURALE ET LES CONTRIBUTIONS DE PRONERA}

RESUMÉ: La raison néolibérale pénètre dans toutes les institutions et dissémine sa vision du monde imposant la gouvernance d'entreprise dans toutes les dimensions du développement. L'éducation est l'une des dimensions les plus touchées par la logique néolibérale. La paysannerie brésilienne en mettant en valeur par le mouvement des travailleurs ruraux sans terre (MST), auprès des enseignants et les chercheurs, a construit le domaine du paradigme de l'éducation au moyen du programme national d'éducation à la réforme agraire (PRONERA). Dans cet article, nous discutons la confrontation de ces deux paradigmes politiques qui font l'objet de conflit dans le terrain de l'éducation. La contribution du PRONERA pendant vingt années d'existence assure cette politique publique comme un élément fondamental à l'éducation paysanne.

Mots-clés: PRONERA. Raison néolibérale. Éducation rurale. Débat paradigmatique.

Amar a terra, e nela plantar semente, a gente cultiva ela, e ela cultiva a gente. A gente cultiva ela, e ela cultiva a gente.

Caminhos alternativos

Zé Pinto

\section{Introdução}

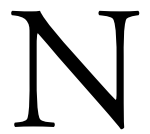

este artigo, apresentamos uma leitura sobre os desafios da educação do campo como um paradigma construído para promover o desenvolvimento dos territórios camponeses. Analisamos o Programa Nacional de Educação na Reforma Agrária (PRONERA) por ser uma das principais referências desse paradigma e uma forma de sucesso e resistência à razão neoliberal, que penetra diversas instituiçóes, impondo a visão empresarial e a governança corporativa. O paradigma da educação do campo é contrário à visão empresarial capitalista e defende a indissociabilidade entre sujeito e território, como está explicitado na epígrafe que inicia este trabalho. Apresentamos o paradigma neoliberal e 
sua influência nas políticas educacionais e os princípios do paradigma da educaçáo do campo para que o leitor possa compreender o debate paradigmático e o fato de o PRONERA estar sendo uma boa razão para mudar o mundo.

A hegemonia do neoliberalismo nos desafia a pensar como mudar o mundo, o que significa para o campesinato a construçáo de seu próprio território a partir de relações sociais familiares, comunitárias, cooperativas, associativas, ou seja, não capitalistas. A razão neoliberal pensa a educação como uma forma de intensificar a lógica empresarial, competitiva, em que as pessoas são equivalentes ao capital, ou capital humano. Portanto, não é uma referência para o campesinato, muito embora haja vários projetos educacionais do paradigma neoliberal em territórios camponeses. A ofensiva da razão neoliberal encontrou no campesinato e na classe trabalhadora uma forte resistência para o seu modelo de desenvolvimento, por essa razão pensamos na importância do campesinato para mudar o mundo. Os dois paradigmas disputam visóes de mundo e de educação centralizada, descentralizada, pública e privada, camponesa e empresarial apontando para modelos distintos de desenvolvimento.

Organizamos este artigo em quatro partes. Na primeira apresentamos uma reflexão sobre as mudanças recentes do mundo e as perspectivas de transformações em curso e como a educação é vista por diversas instituições como condição real de modificação do mundo. Na segunda parte, apresentamos o papel da educação em uma perspectiva neoliberal, empreendedora e empresarial. Em seguida, na terceira parte, discutimos a educação como uma estratégia para mudar o mundo. Por fim, na quarta parte, tomamos o PRONERA como uma evidência desse processo.

Em um mundo urbanizado, são poucas as mentes e olhos que se voltam para o campo. Este texto faz isso, e procura trazer uma leitura crítica de uma experiência que serve de referência para a educação camponesa. Chamamos a atenção do leitor ao debate paradigmático que realizamos, contrapondo autores dos dois paradigmas e demonstrando nossas posturas ao analisar os princípios de ambos.

\section{Razões para mudar o mundo}

O mundo está em movimento constante, impulsionado pela correlação de forças que o disputa. São classes sociais defendendo diferentes sistemas políticos que determinam os usos dos territórios, exploram a natureza e o trabalho. Nesses sistemas, distintas classes sociais determinam o poder de decisão sobre a gestão da acumulação, procurando sustentar a manutenção do sistema, produzindo desigualdades econômicas, políticas e territoriais. Definem as relaçóes entre capital, trabalho, Estado, mercado e tipos de propriedade a partir de suas compreensóes sobre a produção, concentração e distribuição da riqueza comum, da terra e de território. Delimitam os monopólios, fusôes, concorrências sob controle do capital ou do Estado. Ditam as 
tecnologias e os modos de vida, demarcando territórios, liberdade, subordinação e, evidentemente, produzindo diferentes modelos de desenvolvimento. As pessoas que formam as classes desses sistemas determinam a correlaçáo de forças que pode mudar ou manter o sistema. Para Harvey, 2016, essas são contradiçôes que levariam ao fim do capitalismo. E também são contestaçóes que geraram a crise estrutural do socialismo. Os dois sistemas estâo em crise, ainda que o capitalismo se mantenha como força hegemônica. No contexto das disputas, estáo as razóes para mudar o mundo, na superação das desigualdades, na melhoria da qualidade de vida por meio da sustentabilidade, compreendida como recriação das condiçóes naturais de existência e tecnologias apropriadas para o desenvolvimento de relaçóes sociais, em que os poderes de decisão sejam de todas e de todos em uma democracia participativa.

Nas primeiras décadas do século passado, o capitalismo vivia uma de suas profundas crises enquanto nascia a primeira experiência socialista na Rússia. Durante o século XX, diversos movimentos revolucionários triunfaram, implantando o socialismo em seus países. No final do século XX, o capitalismo triunfou sobre o socialismo com as mudanças da União Soviética e daChina, potências socialistas que se tornaram capitalistas. A ascensão do capitalismo e a queda do socialismo são interpretadas pelos neoliberais como uma vitória definitiva do capitalismo. Nas últimas décadas, o mundo foi dominado pela hegemonia neoliberal como está demonstrado por Dardot \& Laval, que estudaram a genealogia do neoliberalismo e sua razão, que controla todas as dimensóes da vida e que se resume à visão empresarial capitalista aplicada às instituições, inclusive ao Estado, ao trabalho e à educação (DARDOT \& LAVAL, 2016). O neoliberalismo é o mais recente paradigma do capitalismo. O pensamento neoliberal não faz uma autocrítica das contradiçóes do capitalismo e procura obstinadamente produzir soluçóes para as constantes crises causadas por elas. A hegemonia do neoliberalismo desafia as forças anticapitalistas a construírem os caminhos da superação do capitalismo, porque há vida após o neoliberalismo, como lembra Boron (2010). Esse é o ponto central da mudança do mundo: a superação do capitalismo.

2017 é um ano simbólico quando nos propomos a pensar sobre as razóes para mudar o mundo, porque marca o centenário da Revolução Russa e, consequentemente, um dos momentos históricos mais importantes para as mudanças do mundo capitalista. É óbvio que as razóes para mudar o mundo hoje não são as mesmas que o fizeram em 1917, porque hoje são mais amplas devido aos resultados da experiência do socialismo no século XX e pelas experiências neoliberais do final do século passado e início do século XXI. Está posta a questão: a superação do capitalismo acontecerá pela recriação do socialismo ou da criação de outro sistema? Se são o mesmo ou se são diferentes, a recriação do socialismo e esse outro nos desafiam a pensar o mundo que queremos mudar. Outro mundo possivel é a ideia que nasceu com o Fórum Social Mundial de 2001, em Porto Alegre (SGUISSARDI, 2001), como manifestação contra a hegemonia neoliberal. Todavia, as evidências desse outro continuam muito mais no plano das ideias, com 
algumas experiências emergentes como o bem viver, em suas variaçôes no Equador e na Bolívia (ACOSTA, 2016), ao mesmo tempo em que experiências socialistas continuam convertendo-se ao neoliberalismo, reforçando sua hegemonia.

A hegemonia do neoliberalismo é demonstrada por sua territorialidade nas instituiçóes privadas e em parte das instituiçóes públicas. Territorialidade pode ser um conceito pouco usual entre os leitores, mas significa que os princípios, critérios e valores do neoliberalismo estáo presentes tanto nas empresas capitalistas quanto em quase todas as instituiçóes públicas. Ou seja, os pensamentos produzidos nos territórios neoliberais, como as empresas capitalistas, fundaçóes, centros de pesquisa, movimentos, associações empresariais e universidades privadas, estão dominando os territórios públicos e governos em todas as instâncias, ministérios, secretarias, universidades e escolas. Dois exemplos são os conceitos neoliberais de empreendedorismo e inovação que estão presentes nas políticas institucionais, reproduzindo a razão neoliberal. Evidente que empreender e inovar não são territórios do neoliberalismo, mas seus intelectuais têm elaborado e propagado esses conceitos para pensar as questôes da sociedade capitalista, fazendo com que seus significados e intencionalidades estejam focados nos problemas do capital. A transposição desses conceitos para as instituições públicas vem carregada da territorialidade empresarial, com princípios e valores neoliberais, como competitividade e produtivismo, que estấo substituindo princípios e valores públicos, como solidariedade, inclusão social e direitos.

Um dos principais territórios do pensamento neoliberal é o mercado, centro do sistema, e a compreensão de um de seus principais teóricos é a garantia de liberdade no capitalismo (FRIEDMAN, 2014; FRIEDMAN \& FRIEDMAN, 2015). É neste contexto que o empreendedorismo tem sentido: pensar o processo produtivo do sistema. Entre seus significados estáo: criatividade, ousadia, produtividade e superação, todos voltados para pensar o modo de produção capitalista, e, por essa razão, o empreendedorismo é visto como uma marca registrada do neoliberalismo. Evidente que o empreendedorismo pode ser usado para pensar o Estado (MAZZUCATO, 2014) e o socialismo (HINDMOOR, 2014; CARNOY, 2009). É necessário pensar a partir dos valores destes territórios. Com essa ideia, reafirmamos que o empreendedorismo não é um território do neoliberalismo, embora este seja o paradigma que mais investe nesse conceito. A hegemonia da razão neoliberal faz com que a maior parte das pessoas associe empreendedorismo como um conceito do neoliberalismo, mas não é. Para além dessa razão, há outros paradigmas que compreendem o mundo a partir da vida, do trabalho, do Estado e das organizaçóes políticas, para além do mercado.

A inovação é outro conceito do qual o neoliberalismo se apropriou e um de seus pensadores o define como fundamento para o desenvolvimento econômico e superação das crises do capitalismo (SCHUMPETER, 1997). A maior parte de nossas instituiçôes pensa a inovação a partir desse referencial; embora não manifestem posicionamento ideológico, encontramos em discursos e textos os con- 
ceitos definidos pela razão neoliberal. A falta de perspectivas de nossas instituiçóes públicas é resultado de sua subordinação à razão neoliberal. Construir perspectivas a partir da inovaçáo para superar o capitalismo náo faz parte das linhas da maioria dos grupos de pesquisa de nossas universidades (OLIVEIRA, 2014). A convicção da razão neoliberal de que o capitalismo é a única via é tão forte nas nossas instituições como é para um dos primeiros formuladores do pensamento neoliberal que defende o sistema acima do sujeito histórico que o produziu (HAYEK, 2010). Esse é o paradigma do capitalismo atual, que se projeta em todas as dimensóes do desenvolvimento, inclusive, é claro, no campo e na educação. A hegemonia da inovação neoliberal aumenta as desigualdades tecnológicas, por exemplo, ao favorecer o modelo hegemônico do agronegócio em detrimento do modelo de desenvolvimento do campesinato. Essa postura subalterna dos governos e universidades produz a inovação destruidora (FERRY, 2015). O neoliberalismo mercantilizou a sociedade, os governos e as universidades, e tornou-se, como já enfatizado, a nova razão do mundo (DARDOT \& LAVAL, 2016).

A hegemonia do neoliberalismo e a crise do socialismo levaram os partidos de esquerda a adotarem as políticas neoliberais com diferenças conjunturais, demarcadas pela aliança com o capital, o apoio de parte dos trabalhadores, movimentos camponeses e uma ação efetiva do Estado na criação de políticas públicas de distribuição de renda. Essas experiências foram denominadas de pós-neoliberais (SADER, 2003; SEGRERA, 2016). No Brasil, a fase pós-neoliberal (governos Lula e Dilma - 2003-2016) foi um período de transição do liberalismo ou um intervalo entre duas fases neoliberais, sendo a primeira com os governos Sarney (1985-1990), Fernando Collor (1990-1992), Itamar Franco (1992-1995) e Fernando Henrique Cardoso (1995-2003), e a segunda com o governo golpista de Michel Temer, que começou no segundo semestre de 2016. Como salientamos, as diferenças entre governos neoliberais e pós-neoliberais são conjunturais: enquanto os neoliberais tendem a ser mais subalternos à razão neoliberal, os governos pós-neoliberais recuperam parcialmente as açóes do Estado em todas as dimensóes do desenvolvimento.

A hegemonia do neoliberalismo encontra resistência nas classes trabalhadora e camponesa organizadas. São esses territórios que a razão neoliberal tem maior dificuldade para dominar. Capital e trabalho disputam modelos de desenvolvimento no campo: o agronegócio como criação das corporaçóes capitalistas e a agroecologia como (re)criação das organizaçóes camponesas. $\mathrm{O}$ poder hegemônico do agronegócio e os discursos de seus ideólogos não conseguem impedir a emergência e a insurgência da agroecologia. São distintos modelos de desenvolvimento territorial em que para cada um o uso da terra e do território é pensado e realizado de modo diferente. São necessárias diversas escalas, relaçóes, tecnologias, educação, configurações, inovações. São visões de mundo que apontam para direçôes opostas e, em parte, sobrepostas, com perspectivas antagônicas em que a natureza e a sociedade são compreendidas como mercadoria e como vida, em que se destrói e se constrói, em que o produto pode ser commodity ou comida. Nesse debate, a 
ideia de consenso não contém o sentido da harmonia, mas o do avesso, do embate. É nessa conjuntura que nasce a educação do campo associada à perspectiva do desenvolvimento territorial do campesinato, resistindo ao avanço do neoliberalismo.

\section{O papel da educação numa perspectiva neoliberal e empreendedora empresarial}

Desde a década de 1970, uma tendência dominante na reforma educacional tem sido a ênfase na descentralização do sistema escolar e num impulso para a participação da "sociedade civil" nas estratégias de desenvolvimento educacional (MCGINN \& WELSH, 1999). Para entender o atual domínio dessas reformas de descentralização que fazem parte da visão neoliberal de transformar o mundo, é necessário examinar o desenvolvimento histórico da educação. Como McGinn e Welsh (1999) descrevem, a forma mais antiga de educaçáo era um modelo de aprendizado em que os professores individuais supervisionavam a educação de membros particulares da comunidade, o que entáo levou ao surgimento de algumas escolas locais administradas pela comunidade. Durante os séculos XIX e XX, os governos começaram a assumir o controle do sistema educacional e a padronizar o conteúdo escolar. Essa centralizaçáo foi facilitada pela urbanização, uma vez que o crescimento das cidades possibilitou a construçáo de escolas que atendessem a grandes populações de estudantes. A expansão da educação também foi impulsionada por sentimentos nacionalistas e pela competição econômica que foram predominantes nesta era. Finalmente, surgiu a ideia de uma nova escola "comum" (MANN, 1848) ou "pública", que substituiu a maioria das instituiçôes de administração privada (MCGINN \& WELSH, 1999).

O desenvolvimento do "raciocínio científico" de origem europeia também contribuiu para a padronização do sistema escolar. Ele ampliou o conhecimento sobre como as pessoas aprendem e como a informaçáo deve ser organizada e, durante a década de 1920, os princípios básicos da "gestão científica" estavam sendo aplicados às escolas da mesma maneira que às corporaçóes e indústrias. Entre muitas consequências, esta aplicação da ciência resultou na divisão de objetivos de aprendizagem em graus, distinçóes entre disciplinas, treinamento formal de professores em conteúdo e método, supervisão do desempenho do professor e avaliações para os estudantes (FREITAS, 2004; TYACK \& TOBIN, 1994).

Até a década de 1960, o foco na centralização das escolas era a tendência em diversos países, e grande parte da realização educacional do século anterior pode ser atribuída a essa padronizaçáo. Por volta da segunda metade do século $\mathrm{XX}$, no entanto, surgiu a ideia de descentralização e controle local do sistema escolar e, na década de 1970, houve um enorme aumento nos governos que implementaram reformas de descentralização, desde os Estados Unidos até a Ásia e a América Latina. Alguns estudiosos (MCGINN \& WELSH, 1999; ZAJDA, 2004) 
argumentam que essa mudança veio do colapso do "consenso keynesiano" que favoreceu governos fortes e do surgimento da globalização financeira que enfraqueceu o Estado e transferiu fundos para a tomada de decisóes baseada nos mercados. Frigotto e Ciavatta explicam que

essas reformas vêm demarcadas por um sentido inverso às experiências do socialismo real e das políticas do Estado de bem-estar social do pós-Segunda Guerra Mundial, lidas pelos intelectuais orgânicos do sistema capital como responsáveis por um desvio dos mecanismos naturais do mercado e, portanto, pela crise (FRIGOTTO \& CIAVATTA, 2003, p. 95).

As novas tecnologias de informação e comunicação também permitiram um alto nível de controle nesses sistemas descentralizados, e os governos centrais começaram a se preocupar com os resultados (tais como as notas dos estudantes em avaliaçóes) e não com os insumos. Já nos anos 1980, a descentralização era vista como uma panaceia da política educacional e, como afirma Zajda (2004, p. 207), a ela se tornou uma nova "postura hegemônica mundial".

Atualmente, governos e organizaçóes internacionais de desenvolvimento continuam a enfatizar e defender a descentralização. No Fórum Mundial de Educação de 2000, a "comunidade internacional comprometeu-se a desenvolver sistemas de governança e gestão educacionais participativas, responsáveis para garantir o engajamento e a participação da sociedade civil em estratégias de desenvolvimento educacional" (MCGINN \& WELSH, 1999, p. 5). A questáo crítica é:

Para que fim queremos a participação da sociedade civil? A motivação para a descentralização vem da crença de que aumentará a eficiência de uma lenta burocracia estatal, aumentará a capacidade de resposta às necessidades e situaçôes particulares, promoverá uma maior participação da população local, resultará em melhor prestação de serviços e facilitará a busca de novos recursos (MACLURE, 1994).

Assim, podemos colocar as justificativas para a descentralizaçáo em três grandes categorias: motivação pela eficiência, processo político e interesse financeiro.

Agências de desenvolvimento internacional, como o Banco Mundial, têm sido vanguarda na defesa da descentralização baseada no argumento da eficiência de mercado. $\mathrm{O}$ Banco Mundial começou a investir na educação no início da década de 1970, sob a presidência de Robert McNamara. De acordo com Roberto Leher (1999), as intervenções estavam relacionadas também com os interesses de países capitalistas influentes em defender a "segurança" e a "contrainsurgência". McNamara reafirmou, em 1972, o propósito de "resguardar a estabilidade do mundo ocidental". Nesta perspectiva, durante o seu mandato (1968-1981): 
McNamara e os demais dirigentes do Banco abandonaram gradativamente o desenvolvimentismo e a política de substituição das importaçóes, deslocando o binômio pobreza-segurança para o centro das preocupaçóes; é neste contexto que a instituição passa a atuar verdadeiramente na educação (LEHER, 1999, p. 22).

McNamara criou o Departamento de Educação do Banco Mundial, que priorizou principalmente métodos de educação não formal e educação de adultos. No entanto, durante esse período, a ideia de capital humano estava se tornando dominante: um investimento na educação e nas qualificações dos povos é uma forma de capital que pode facilitar o sucesso pessoal no mercado de trabalho e aumentar a prosperidade econômica de uma nação (MUNDY, 2002). Esse conceito foi popularizado por Theodore Schultz, um economista neoclássico que obteve seu doutorado em Economia Agrícola. Schultz (1959) escreveu que

conhecimento novo e útil é, sem dúvida, de importância estratégica tanto para mudar a natureza das habilidades úteis que são de maior valor, quanto para alterar e melhorar a qualidade das instalaçóes e equipamentos físicos que empregamos (SCHULTZ, 1959, p. 116).

Esse paradigma neoliberal foi importante para a expansão educacional, pois deu ao Departamento de Educaçáo do Banco Mundial o estatuto científico necessário para racionalizar o investimento educacional (BONAL, 2004; LEHER, 1999; MUNDY, 2002). "O Banco abraçou o ideário neoliberal e, diante da vulnerabilidade dos países endividados” (LEHER, 1999, p. 23).

Consequentemente, durante a presidência de McNamara, foram disponibilizados mais fundos para a educaçáo primária nos países em desenvolvimento, de modo que os empréstimos para a educação primária passaram de 4,2\%, em 1963-1969, para 22,9\%, em 1975-1979 (MUNDY, 2002). Junto com a aplicação da teoria do capital humano, o Banco também desenvolveu um estudo de taxa de retorno que poderia mostrar a eficiência relativa de vários insumos no sistema educacional (LUCAS \& LEHER, 2001; MUNDY, 2002). Ao combinar capital humano e estudos de taxa de retorno, o Banco Mundial teve sua justificativa econômica para o investimento em educação sem parecer estar investindo em caridade.

$\mathrm{O}$ argumento cumulativo era que a educação poderia ser melhorada sem aumentos maciços nas despesas, desde que a eficiência e o financiamento dos sistemas educacionais fossem melhorados através de medidas tais como o aumento da provisão privada, sujeição do sistema público a pressóes provocadas pela demanda e introdução de encargos para os beneficiários (MUNDY, 2002, p. 490). 
A forma como esse investimento educativo foi feito enfatizou o papel dos pais como consumidores e a necessidade do controle descentralizado do sistema escolar para evitar custos ao governo central.

A crise da dívida no hemisfério sul, durante a década de 1990, foi outro fator essencial para a expansão dos projetos educacionais do Banco Mundial. Durante a década de 1970, houve um rápido aumento dos empréstimos internacionais dos bancos aos países em desenvolvimento (LEHER, 1999; LUCAS \& LEHER, 2001). No entanto, em 1979, esse empréstimo "livre para todos" terminou quando a Reserva Federal dos Estados Unidos aumentou as taxas de juros e dezenas de países em desenvolvimento não podiam mais pagar seus empréstimos. Essa crise da dívida internacional entre as naçôes do hemisfério sul foi criada pela estratégia neoliberal de Políticas de Ajuste Estrutural, quando o FMI e o Banco Mundial cobraram os países em dívida e ofereceram empréstimos condicionados à neoliberalização de suas economias, à redução dos tamanhos de seus governos, à desregulação de suas indústrias, à eliminação das tarifas e ao investimento na produção de "culturas de rendimento" (WOODS, 2006).

Inicialmente, pode ter parecido que o advento da nova abordagem do Banco para empréstimos ao desenvolvimento simplesmente empurraria a educação e investimento de capital humano para lados distintos. Mas, em vez disso, os empréstimos de ajuste criaram uma rica oportunidade para os funcionários do setor educacional do Banco construírem uma abordagem mais expansiva e doutrinária para os empréstimos ao setor educacional (MUNDY, 2002, p. 489).

Portanto, esses três fatores - o uso da teoria do capital humano, o desenvolvimento de um estudo de taxa de retorno para a educação e a crise da dívida internacional - prepararam o cenário para que o Banco Mundial e outros sujeitos neoliberais tornassem a educação uma estratégia central em sua proposta de desenvolvimento internacional e mudança social. O processo de reforma educacional no Chile, durante os anos 1980, é um exemplo da implementação do paradigma neoliberal de desenvolvimento educacional. As reformas chilenas foram uma forma de descentralização baseada na eficiência de mercado, na qual a "comunidade" é vista como um agregado de consumidores individuais, em vez de uma coletividade politicamente mobilizada. O papel que é dado a essa comunidade imaginada é um conjunto de mecanismos de prestaçáo de contas, como testes padronizados e vouchers, que permitem que os pais responsabilizem as escolas pelas suas necessidades. No Brasil, as reformas neoliberais na educação começaram no anos 1990 com Fernando Henrique Cardoso e, segundo Freitas, foram uma tentativa de acabar com o pensamento progressista (FREITAS, 2004). Observa-se, portanto, que o paradigma neoliberal tem se apropriado de um conjunto de políticas para direcionar a educaçáo ao encontro de seus princípios. Uma das resistências a este projeto é a educação do campo. 


\section{Educação do campo como estratégia para mudar o mundo}

Internacionalmente, os governos têm-se dedicado a expandir as oportunidades educacionais e melhorar a qualidade da educação, de uma parte por causa da constante pressão popular, especialmente de movimentos socioterritoriais organizados que têm, inclusive, contribuído com a criação de políticas educacionais, como é o exemplo do PRONERA, estudado neste artigo. De outra parte porque a educação, numa perspectiva dicotômica, passou a ser vista como uma panaceia para uma série de problemas econômicos e sociais. Na página inicial do Departamento de Educação do Banco Mundial, afirma-se que a educação é "um dos instrumentos mais poderosos para a redução da pobreza e da desigualdade" e, como McGinn (2002) argumenta, "a educação deve contribuir também para o crescimento econômico, a harmonia social e a democracia, assim como para a aquisição de habilidades e conhecimentos" (MCGINN, 2002, p. 15). Os governos e as agências internacionais de desenvolvimento não veem mais o propósito das escolas como simplesmente educar novos alunos, mas, além disso, a educação também deve ser responsável pela reduçâo da pobreza e pela conquista da "harmonia social" e da "igualdade". Neste tópico, tomamos um olhar crítico sobre como a educação é encarada como uma estratégia "para transformar o mundo" a partir de paradigmas distintos discutidos neste artigo.

A educação é um direito, condição essencial para o desenvolvimento. Essas são referências fundamentais para compreender o processo de construção da educação do campo. Embora essas referências sejam básicas, elas estão em risco permanente, porque o direito pode náo ser respeitado, inclusive pelo Estado, porque a educaçáo pode ser vista como um serviço ou uma mercadoria pela razão neoliberal, porque pode ser precarizada no que se refere a infraestrutura das escolas, equipamentos, materiais, recursos didáticos e salários dos professores, comprometendo a qualidade dos conteúdos e mais uma série de problemas que a educação brasileira tem enfrentado em todos os níveis. Em escala mundial, a Organização das Nações Unidas para a Educação, a Ciência e a Cultura (UNESCO) publica anualmente o Relatório de Monitoramento Global da Educação (UNES$\mathrm{CO}, 2016)$, que nos permite visualizar um mapa dos avanços e retrocessos da educação pelo mundo. Para a UNESCO (2016, p. 5),

uma educação melhor leva a maior prosperidade, à melhoria da agricultura, a melhores resultados de saúde, a menos violência, a mais igualdade entre os sexos, a capitais sociais mais elevados e a um ambiente natural melhorado. A educação é a chave para ajudar as pessoas em todo o mundo a compreender por que o desenvolvimento sustentável é um conceito tão vital para nosso futuro comum.

O Relatório de Monitoramento Global da Educação também mostra que 
a educação não realizará todo o seu potencial a menos que as taxas de participação aumentem de forma contundente e o desenvolvimento sustentável guie a reforma do sistema educacional. Ele também alerta para o impacto destrutivo que mudanças climáticas, conflitos, consumo insustentável e a lacuna cada vez maior entre ricos e pobres têm sobre a educação. É necessária uma mudança drástica para criarmos futuros sustentáveis para todos (UNESCO, 2016, p. 61).

Mudança, transformação e superação são palavras recorrentes nos documentos referentes à educação. Entender a educação numa perspectiva territorial é associá-la ao desenvolvimento, às transformaçóes e à superação. Isso significa que a educação está relacionada com todas as outras dimensóes. O que é diferente de uma perspectiva dicotômica em que a educação é separada das outras dimensôes — da política, da econômica, da cultural —, mas é vista como solução para todos os problemas. A educação como condição e a educação como solução são paradigmas distintos que evidenciamos neste trabalho. Em geral as instituições assumem mais a postura dicotômica porque não exige compromisso como a transformação e a superação. Por essa razão, o Estado e as comunidades são instituições fundamentais para cuidar da educação, porque não podem separá-la do território em que está inserida. São instituições territorializadas, enraizadas, diferentes das que não possuem vínculo com o território, que fazem a transposição de seus valores e princípios exteriores para o território da escola, ignorando os princípios e valores das comunidades, separando a educação do território. As instituiçóes precisam ter vínculos territoriais com a escola.

Na origem da educação do campo, está a indissociabilidade com o território. É assim que compreendemos os vínculos entre educação e território, porque um não existe sem o outro. Toda educação produz um território e por ele é produzida. Está nessa origem o Manifesto das Educadoras e dos Educadores da Reforma Agrária ao Povo Brasileiro. Em diversas partes desse manifesto da educação está a ideia de transformação, a visão da igualdade, que vai muito além das paredes da escola, e chega ao território camponês. As declarações números 2, 3 e 7 do manifesto dizem o seguinte:

2) Manifestamos nossa profunda indignação diante da miséria e das injustiças que estáo destruindo nosso país, e compartilhamos do sonho da construçáo de um novo Projeto de desenvolvimento para o Brasil, um Projeto do povo Brasileiro.

3) Compreendemos que a educação sozinha não resolve os problemas do povo, mas é um elemento fundamental nos processos de transformação social.

7) Queremos uma escola que se deixe ocupar pelas questóes de nosso tempo, que ajude no fortalecimento das lutas sociais e na soluçáo dos problemas concretos de cada comunidade e do país (MST, 1997). 
O manifesto foi publicado como documento do I Encontro Nacional das Educadoras e Educadores da Reforma Agrária (ENERA), realizado de 28 a 31 de julho de 1997 na Universidade de Brasília. Foi nesse evento que nasceu a proposta de criação de uma das primeiras políticas públicas de educação do campo, o PRONERA (FERNANDES, 2000, p. 220; MOLINA, 2003, p. 50). Essa política se consolidou como um exemplo de educação do campo para os assentamentos de reforma agrária e tornou-se referência para a criação de outras políticas educacionais.

\section{A contribuição do PRONERA}

A agricultura camponesa não teve uma política educacional voltada para o desenvolvimento de seus territórios até a criação do PRONERA. A inexistência dessa política deve-se ao fato de que os governos náo reconheceram o campesinato como modelo estratégico para o desenvolvimento. A hegemonia do agronegócio manteve o controle político sobre os governos neoliberais e pós-neoliberais impondo seu modelo de produçáo de commodities. Foram as lutas do campesinato pela terra, reforma agrária, para viver dignamente, para produzir alimentos, que se transformaram em uma luta territorial, em que a educaçáo do campo é indissociada do desenvolvimento. Foi nessa circunstância que nasceu a educação do campo, tendo o PRONERA como uma política pública nacional, defendida pelos movimentos camponeses que resistiram e persistiram no processo de consolidação e sua institucionalização em 2009, com a Lei no 11.947. A sua manutenção - e de outras políticas públicas de educação do campo - é uma disputa permanente com o paradigma neoliberal. Em seus quase 20 anos de existência, o PRONERA contribuiu para fortalecer a identidade camponesa por meio do acesso à educação em todos os níveis. Promoveu a formação profissional em cursos de nível médio e superior por meio de acordos de cooperação com diversas universidades brasileiras. Contribuiu também com as experiências agroecológicas e com a produção de tecnologias, inovando e criando lideranças de comunidades, cooperativas e associaçóes de produtores (IPEA, 2016).

De acordo com o relatório da II Pesquisa Nacional de Educação em Áreas de Reforma Agrária (IPEA, 2015), o PRONERA promoveu — desde sua criação, em 1998, até 2011 - a realização de 320 cursos nos níveis: educação de jovens e adultos (EJA) fundamental, ensino médio e ensino superior - envolvendo 82 instituições de ensino, 38 organizaçóes demandantes e 244 parceiros, com a participação de 164.894 educandos. Esses cursos qualificaram a formação educacional e profissional de trabalhadoras e trabalhadores, contribuindo com a qualidade de vida e desenvolvendo seus territórios. No período, foram 320 cursos realizados em 880 municípios e em todas as unidades da federação, como evidenciado na Figura 1. Nenhuma outra política educacional criou tantos cur- 
sos como o PRONERA para a população camponesa em áreas de reforma agrária. Chegou no que outras políticas não chegaram, levando condições de acesso à educação em diversos níveis, como apresentado no Gráfico 1. A maioria dos cursos foi de alfabetização de jovens e adultos, o que contribuiu para diminuir o índice de analfabetismo. A diversidade de cursos de nível médio foi resultado da procura pela profissionalização para a formação de jovens lideranças para as comunidades, como também profissionais de nível superior de fora do território, mas que passaram a atuar nos assentamentos, com a criativa experiência dos cursos de Residência Agrária. Esses graduados de diversas áreas do conhecimento atuaram nos assentamentos e em políticas de desenvolvimento. Destacamos o acesso ao ensino superior com a criação de 54 cursos no período, como, por exemplo: pedagogia, história, geografia, sociologia, ciências naturais, agronomia, direito e medicina veterinária, entre outros. Dessas experiências, surgiram

\section{Figura 1}

Cursos do PRONERA por município de realização (1998-2011).

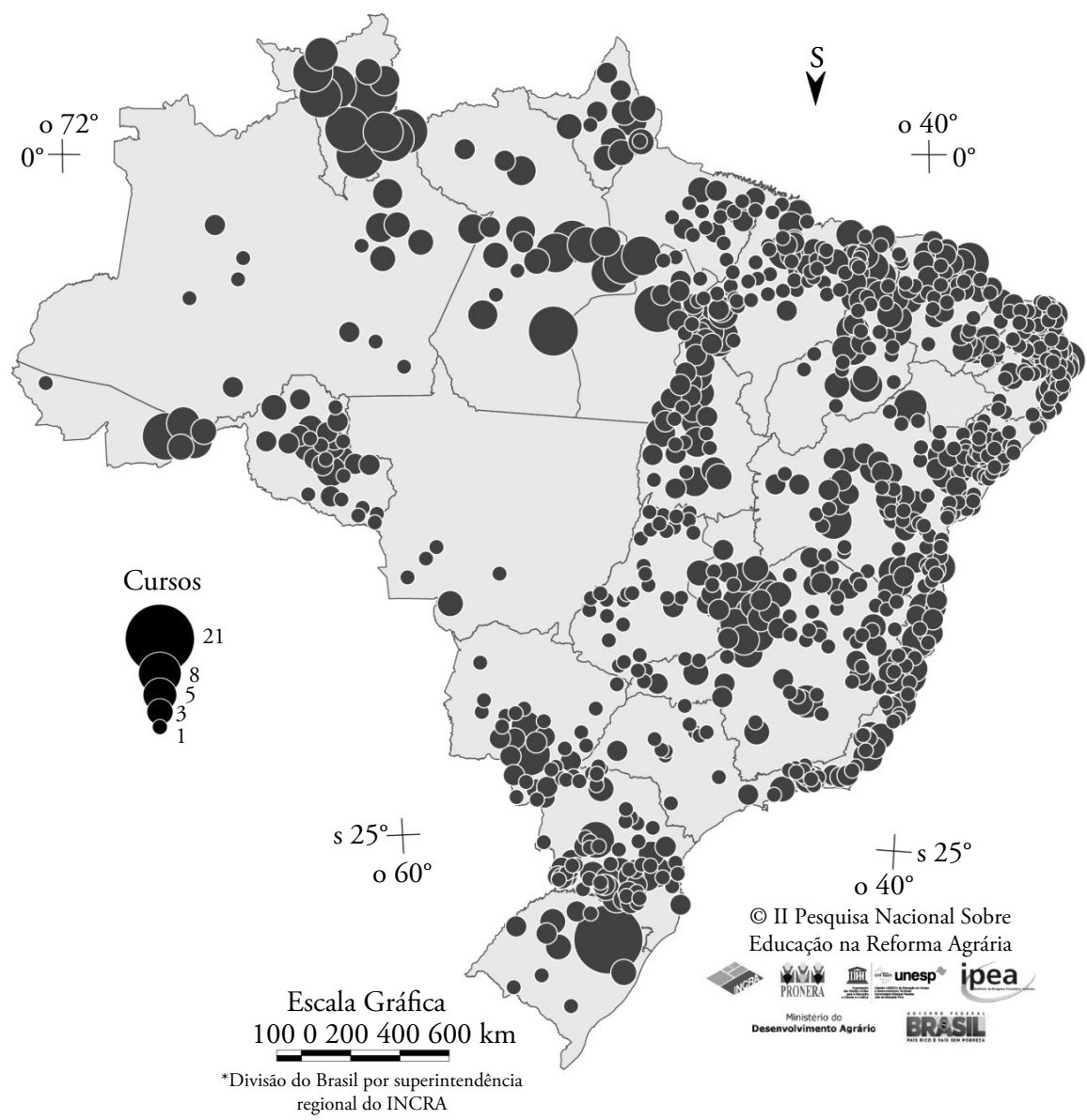


vários cursos de pós-graduação em educação do campo e desenvolvimento territorial, como é o caso do Programa de Pós-Graduação em Desenvolvimento Territorial na América Latina e Caribe da Universidade Estadual Paulista "Júlio de Mesquita Filho" (UNESP).

A participação dos educandos por modalidade de ensino pode ser vista no Gráfico 2, que revela a demanda por cursos de alfabetização, sendo que cada curso teve dezenas de turmas em cada comunidade. Esta é uma condição fundamental da educação do campo: a escola no território, ou seja, na comunidade. Evidente que nem sempre é possível atender esse princípio, mas é sempre a melhor opção. O gráfico também revela o afunilamento dos níveis, impedindo que a maior parte dos alunos continue a estudar. A condição para superar esse dilema é a ampliação do PRONERA, o que significa intensificar a disputa pela

\section{Gráfico 1}

Cursos do PRONERA por modalidade (1998-2011).

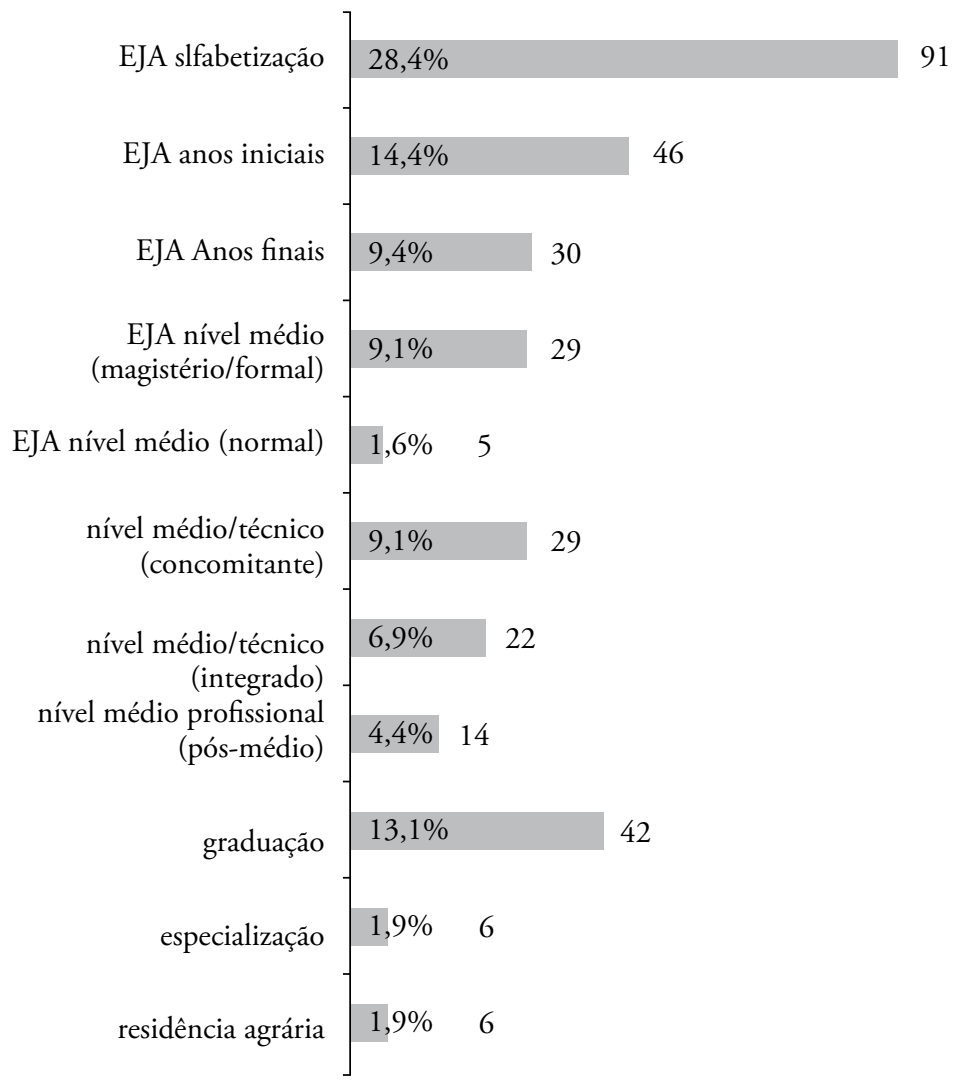


educação do campo. Para uma visão geral do número de educandos e cursos por superintendência do Instituto Nacional de Colonização e Reforma Agrária (INCRA), a Tabela 1 mostra que os estados do Maranhão, Bahia, Minas Gerais e Pará foram os que mais apresentaram demanda, inclusive da educaçáo de jovens e adultos. A maior delas é neste nível que muda de acordo com os estados. Observa-se que no Rio Grande do Sul, Maranhão, Bahia e Pará há maior demanda por ensino médio enquanto para o ensino superior no estado da Paraíba. A Figura 2 permite ver a distribuição espacial dos educandos por nível e munícipio de origem, enquanto a Figura 3 registra os territórios de origens e a Figura 4 mostra que a maioria dos educandos veio dos assentamentos rurais. A expansão do PRONERA para os territórios quilombolas, comunidades tradicionais, Reserva de Desenvolvimento Sustentável (RDS), Florestas Nacionais (FLONA) e Reservas Extrativistas (RESEX), entre tantas outras comunidades

\section{Gráfico 2}

Educandos ingressantes/matrículas em cursos do PRONERA por modalidade (1998-2011).

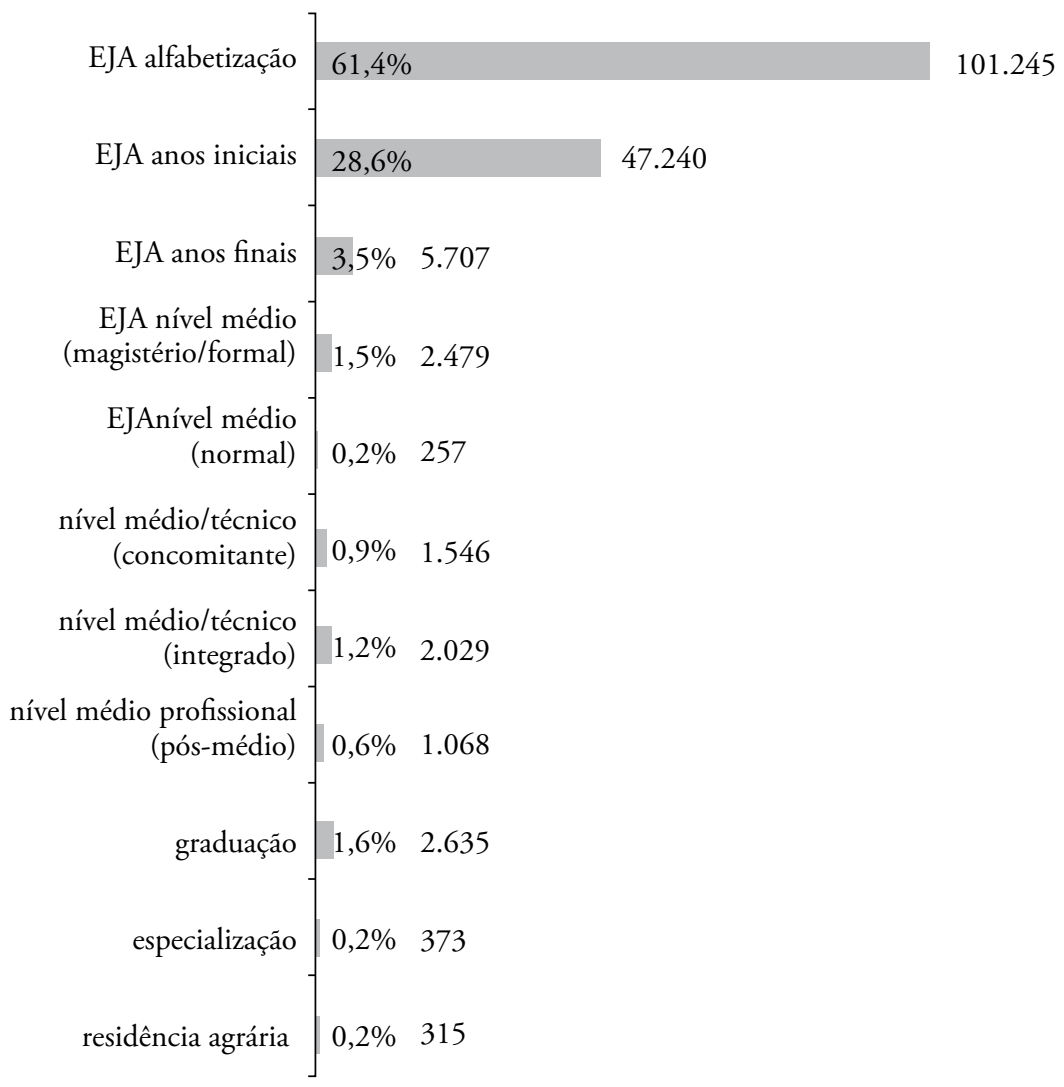




\section{Tabela 1}

Educandos ingressantes/matrículas em cursos do PRONERA por superintendência do INCRA e nível.

\begin{tabular}{|c|c|c|c|c|c|}
\hline $\begin{array}{l}\text { Número da } \\
\text { superintendência } \\
\text { do INCRA }\end{array}$ & $\begin{array}{c}\text { Nome da } \\
\text { superintendência do } \\
\text { INCRA }\end{array}$ & $\begin{array}{c}\text { EJA } \\
\text { fundamental }\end{array}$ & $\begin{array}{l}\text { Ensino } \\
\text { médio }\end{array}$ & $\begin{array}{l}\text { Ensino } \\
\text { superior }\end{array}$ & Total \\
\hline SR-14 & Acre & 2.433 & 130 & 87 & 2.650 \\
\hline SR-22 & Alagoas & 340 & 13 & 0 & 353 \\
\hline SR-21 & Amapá & 1.708 & 0 & 0 & 1.708 \\
\hline SR-15 & Amazonas & 5.519 & 0 & 200 & 5.719 \\
\hline SR-05 & Bahia & 20.835 & 698 & 234 & 21.767 \\
\hline SR-02 & Ceará & 7.287 & 303 & 164 & 7.754 \\
\hline SR-28 & $\begin{array}{l}\text { Distrito Federal } \\
\text { e entorno }\end{array}$ & 2.550 & 87 & 76 & 2.713 \\
\hline SR-20 & Espiríto santo & 1.756 & 60 & 150 & 1.966 \\
\hline SR-04 & Goiás & 1.415 & 0 & 79 & 1.494 \\
\hline SR-12 & Maranhão & 24.946 & 1.102 & 0 & 26.048 \\
\hline SR-13 & Mato Grosso & 1.648 & 0 & 195 & 1.843 \\
\hline SR-16 & Mato Grosso do Sul & 4.712 & 492 & 0 & 5.204 \\
\hline SR-06 & Minas Gerais & 12.195 & 85 & 116 & 12.396 \\
\hline SR-01 & Pará/Belém & 5.001 & 40 & 100 & 5.141 \\
\hline SR-27 & Pará/Marabá & 3.160 & 336 & 198 & 3.694 \\
\hline SR-30 & Pará/Santarém & 10.253 & 257 & 0 & 10.510 \\
\hline SR-18 & Paraíba & 6.091 & 522 & 280 & 6.893 \\
\hline SR-09 & Paraná & 1.926 & 459 & 266 & 2.651 \\
\hline SR-03 & Pernambuco & 3.166 & 139 & 50 & 3.355 \\
\hline SR-29 & $\begin{array}{l}\text { Pernambuco/Médio } \\
\text { São Francisco }\end{array}$ & 0 & 184 & 125 & 309 \\
\hline SR-24 & Piauí & 8.410 & 160 & 0 & 8.570 \\
\hline SR-07 & Rio de Janeiro & 1.180 & 0 & 0 & 1.180 \\
\hline SR-19 & Rio Grande do Norte & 1.238 & 378 & 243 & 1.859 \\
\hline SR-11 & Rio Grande do Sul & 2.924 & 1.029 & 167 & 4.120 \\
\hline SR-17 & Rondônia & 5.873 & 127 & 60 & 6.060 \\
\hline SR-25 & Roraima & 4.966 & 200 & 200 & 5.366 \\
\hline SR-10 & Santa Catarina & 6.012 & 100 & 106 & 6.218 \\
\hline SR-08 & São Paulo & 830 & 267 & 117 & 1.214 \\
\hline SR-23 & Sergipe & 1.391 & 84 & 110 & 1.585 \\
\hline SR-26 & Tocantins & 4.427 & 127 & 0 & 4.554 \\
\hline Total & Brasil & 154.192 & 7.379 & 3.323 & 164.894 \\
\hline
\end{tabular}

INCRA: Instituto Nacional de Colonização e Reforma Agrária; EJA: educação de jovens e adultos; SR: superintendência. 
camponesas, foi uma estratégia do governo federal de levar as políticas públicas para estes territórios e incluir nos números da reforma agrária. A contribuição do PRONERA, em seus 20 anos de existência, assegura essa política pública como fundamental para a educação camponesa.

Os dados analisados e as realidades transformadas evidenciam que o PRONERA se tornou uma referência de política pública pelo seu potencial de mudar o mundo. É importante compreender que essa transformaçáo é um processo multiescalar que possui uma longa temporalidade em movimento constante. Essa política expandiu a educação do campo para todo o Brasil e possibilitou a milhares de pessoas o acesso à educação em todos os níveis. Isto é um exemplo de como se muda o mundo.

\section{Figura 2}

Educandos/matrículas de cursos do PRONERA (1998-2011) por município de origem do educando e nível.
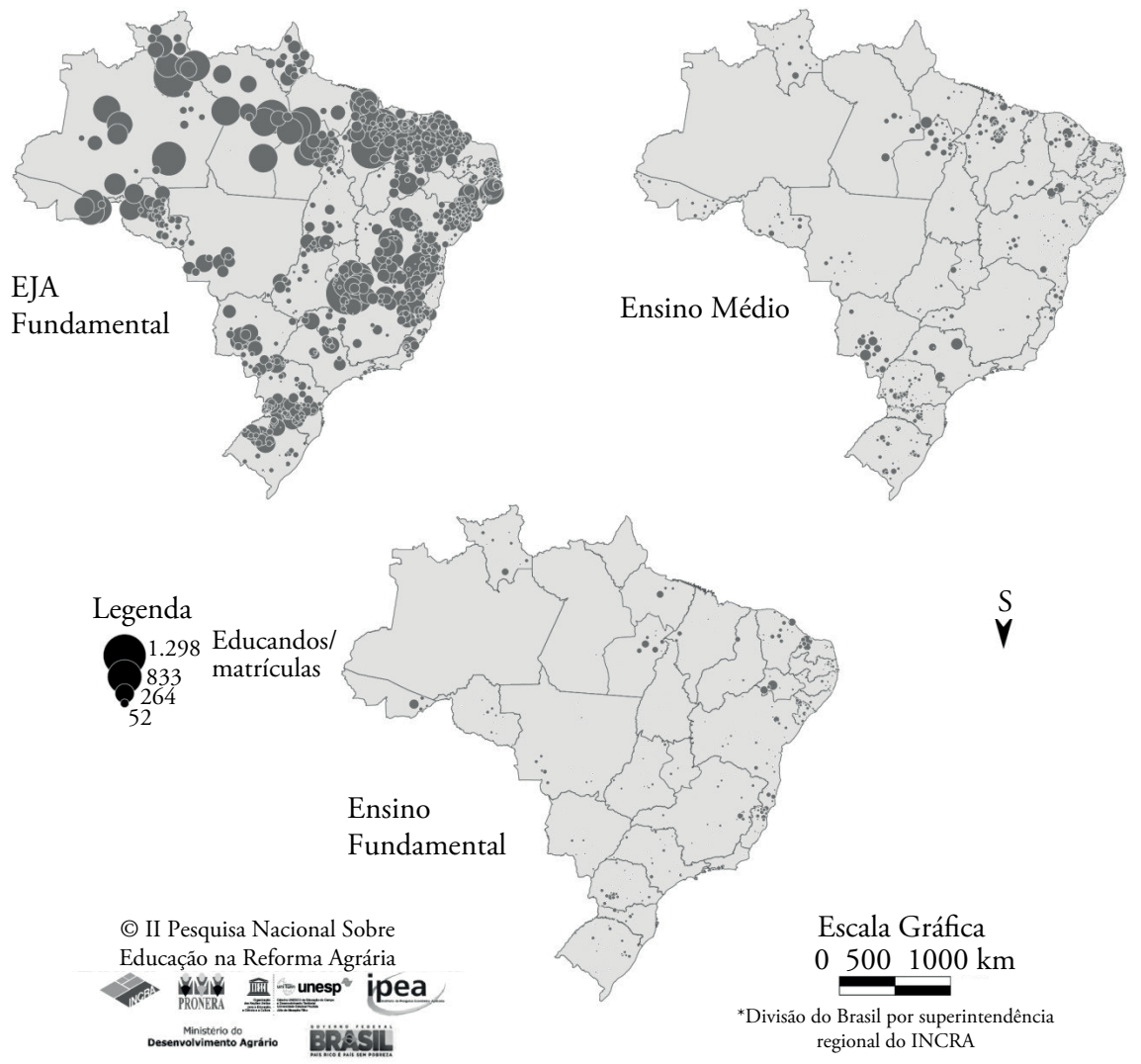


\section{Figura 3}

Educandos/matriculados em cursos do

PRONERA por território de origem (1998-2011).
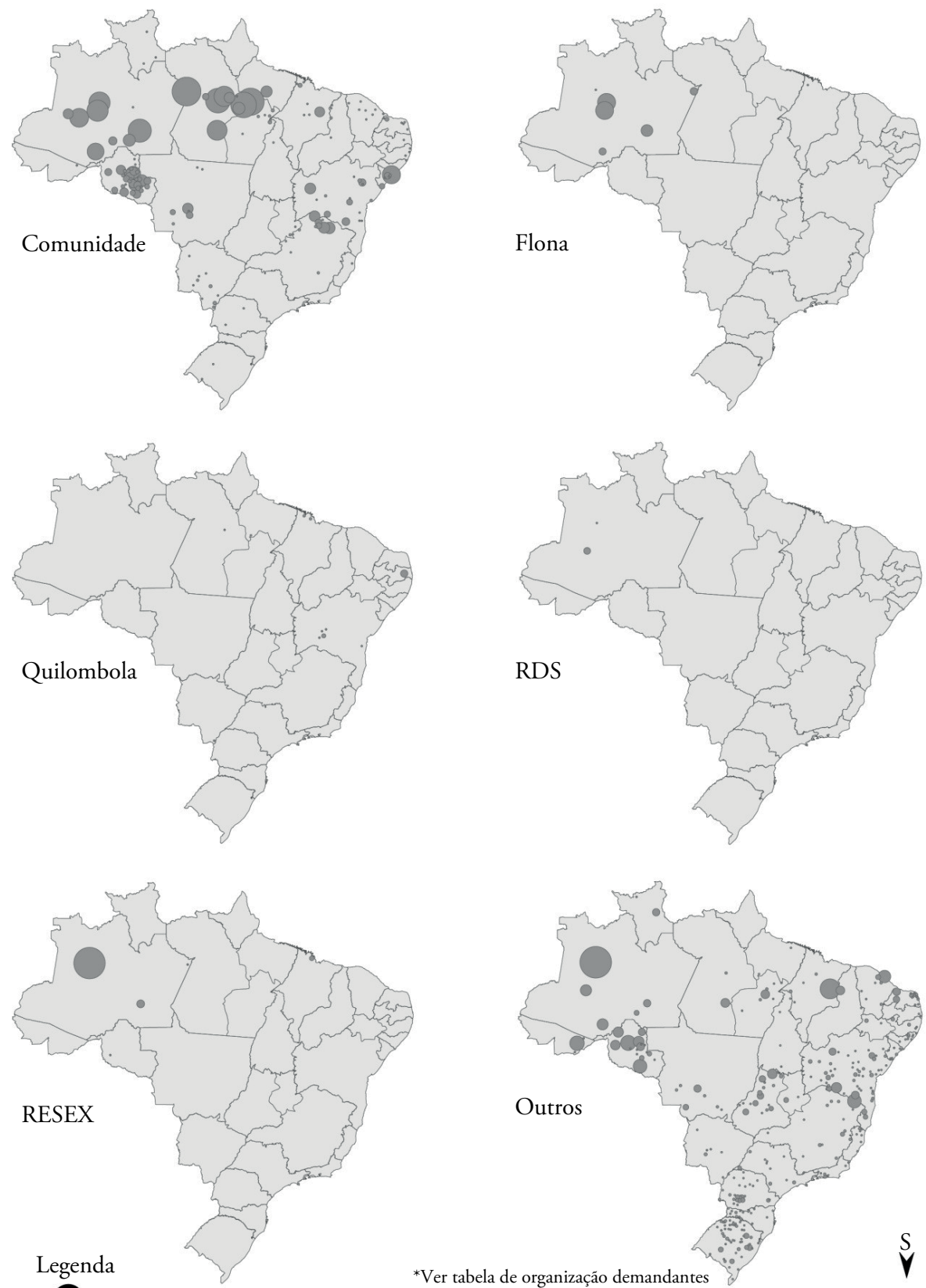

*Ver tabela de organização demandantes

s

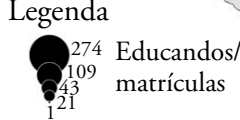

(C) II Pesquisa Nacional Sobre

Educaçáo na Reforma Agrária

Escala Gráfica

Provi

$05001000 \mathrm{~km}$

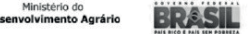

*Divisăo do Brasil por superintendência regional do INCRA 


\section{Figura 4}

Educandos/matriculados em cursos do PRONERA provenientes de assentamentos rurais (1998-2011).

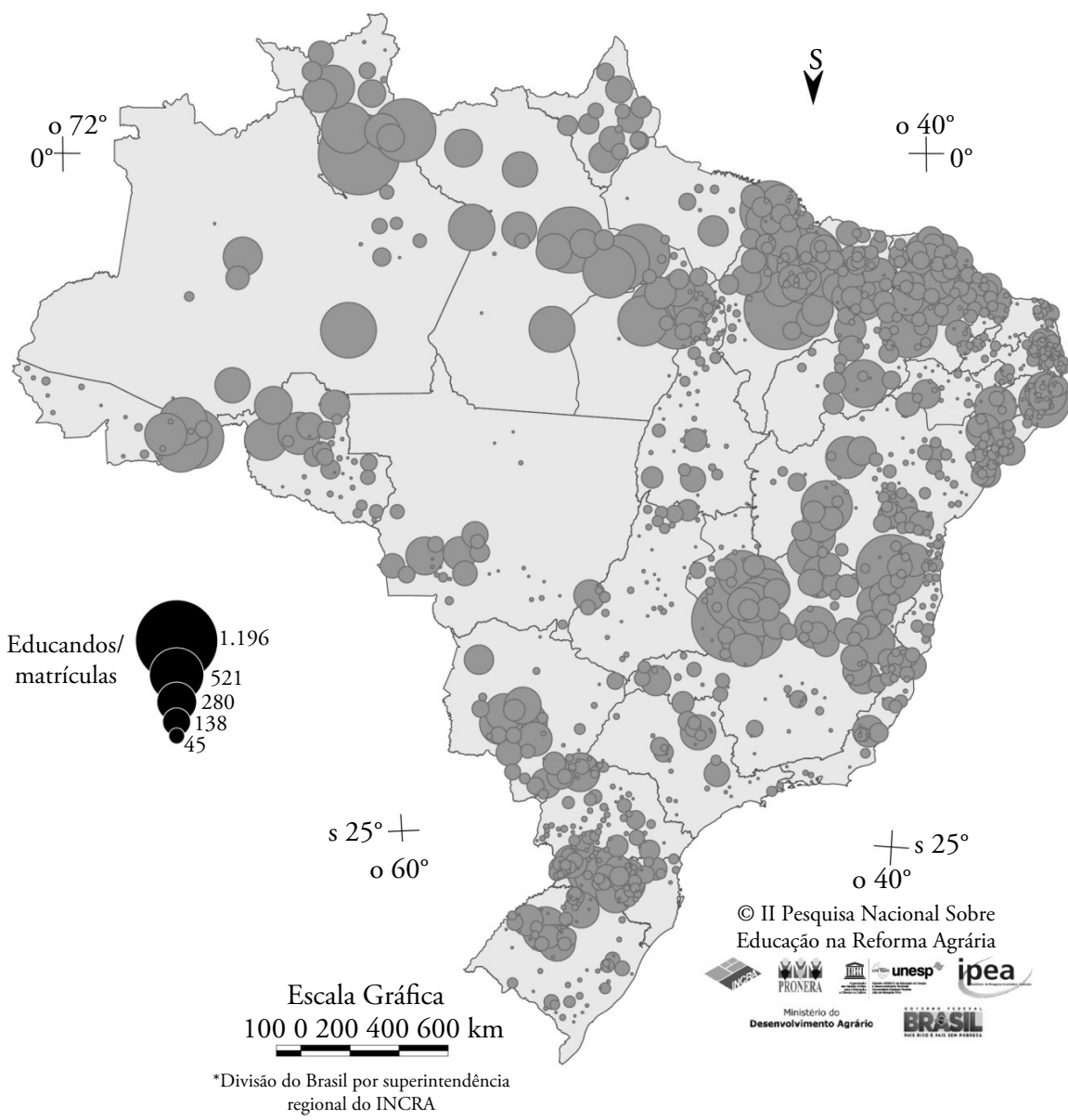

\section{Considerações finais}

A educação está no centro da disputa das diferentes razóes para mudar o mundo. Atualmente a razão hegemônica para dar continuidade a essa mudança está baseada na lógica neoliberal, em que a sociedade é submetida à lógica do mercado. Nessa perspectiva os esforços de reforma educacional representam as teorias de desenvolvimento educacional dominantes, promovidas pelos economistas neoclássicos e pelo Banco Mundial, e têm sua base numa compreensão neoliberal do mercado e da relação entre escolaridade e economia. A "comunidade" é vista 
como um agregado de consumidores individuais que têm a habilidade de escolher a escola que seria melhor para seus filhos. A visão de igualdade nesse modelo é a "igualdade de escolha", ou seja, a capacidade dos pais de ter controle total sobre onde seu filho vai estudar. A terceirização das escolas públicas para empresas privada amplia as opçóes, e é considerada uma forma de inovação e empreendedorismo em contraste com o sistema "ineficiente" gestado pelo Estado. A educação de "qualidade" é vista como uma forma de investimento no capital humano e no crescimento econômico do país.

Entretanto, as classes dominantes, que estão apoiando essa razão neoliberal para mudar o mundo, não são as únicas "inovadoras" das políticas públicas. O caso do PRONERA mostra que as comunidades camponesas também podem ser protagonistas de sua própria história e inovar com formas de gestáo educacional, mas a partir de outra perspectiva e de outra razão para mudar o mundo. A razão contra-hegemônica para mudar o mundo é baseada na ideia de que a educação é um direito, condição essencial para o desenvolvimento sustentável do território camponês. Uma diversidade de cursos foi criada na experiência do PRONERA, incluindo os de direito, agronomia, pedagogia, geografia, veterinária entre outros. O PRONERA oferece esses cursos para os povos do campo que sempre foram excluídos das universidades. As comunidades camponesas podem participar na gestáo do PRONERA junto com as universidades e o Estado. O propósito educacional é desenvolver a capacidade técnica do educando e, além disso, cultivar sua habilidade para analisar o ambiente político, econômico e social, assim se tornando um sujeito da luta social. A "inovação" que o PRONERA traz é rejeitar a ideia de que educação é treinar os estudantes para serem competitivos na economia global, porque esta os exclui. É também usar a educação para outra razão para transformar o mundo, que é formar uma nova geração de militantes para modificar o campo brasileiro, defendendo e criando territórios, desde uma perspectiva camponesa.

\section{Referências}

ACOSTA, A. O bem viver: $u$ ma oportunidade para imaginar outros mundos. São Paulo: Autonomia Literária/Elefante, 2016.

BONAL, $\mathrm{X}$. Is the world bank education policy adequate for fighting poverty? Some evidence from Latin America. International Journal of Educational Development, v. 24, p. 649-666, 2004.

BORON, A. O socialismo no século XXI: há vida após o neoliberalismo? São Paulo: Expressão Popular, 2010.

CARNOY, M. A vantagem acadêmica de Cuba. Sáo Paulo: Ediouro, 2009.

DARDOT, P.; LAVAL, C. A nova razão do mundo: ensaio sobre a sociedade neoliberal. São Paulo: Boitempo, 2016. 
FERNANDES, B.M. A formação do MST no Brasil. Petrópolis: Vozes, 2000.

FERRY, L. A inovação destruidora. Rio de Janeiro: Objetiva, 2015.

FREITAS, L.C. Avaliação e as reformas dos anos de 1990: novas formas de exclusão, velhas formas de subordinação. Educação e Sociedade, v. 25, n. 86, p. 133-170, 2004.

FRIEDMAN, M. Capitalismo e liberdade. Rio de Janeiro: LTC, 2014.

FRIEDMAN, M.; FRIEDMAN, R. Livre para escolher. Rio de Janeiro: Record, 2015.

FRIGOTTO, G.; CIAVATTA, M. Educação básica no Brasil na década de 1990: subordinação ativa e consentida à lógica do mercado. Educação e Sociedade, v. 24, n. 82, p. 93-130, 2003.

HARVEY, D. 17 contradiçóes e o fim do capitalismo. São Paulo: Boitempo, 2016.

HAYEK, F. O caminho da servidão. São Paulo: Instituto Ludwig von Mises Brasil, 2010.

HINDMOOR, A. Socialism and entrepreneurship: a rational choice. London: School of Economics and Political Science, 2014.

INSTITUTO DE PESQUISA ECONÔMICA APLICADA (IPEA). Relatório da II Pesquisa Nacional de Educação em Áreas de Reforma Agrária. Brasília, 2015.

. Relatório da II Pesquisa Nacional de Educação em Áreas de Reforma Agrária: pesquisa qualitativa no Estado do Paraná. Rio de Janeiro, 2016.

LEHER, R. Um novo senhor da educação? A política educacional do Banco Mundial para a periferia do capitalismo. Outubro, v. 1, n. 3, p. 19-30, 1999.

LUCAS, L.C.G.; LEHER, R. Aonde vai a educação pública brasileira? Educação e Sociedade, v. 22, n. 77, 2001.

MACLURE, R. Misplaced assumptions of decentralization and participation in rural communities: primary school reform in Burkina Faso. Comparative Education, v. 30, n. 3, p. 239-254, 1994.

MAZZUCATO, M. O Estado empreendedor: desmascarando o mito setor público versus setor privado. São Paulo: Portfolio-Peguin, 2014.

MANN, H. Twelfth Annual Report to the Secretary of Massachusetts State Board of Education. [S.l.: s.n.], 1848.

MCGINN, N.F. International and national trends in local governance of education. Paris: UNESCO, 2002.

MCGINN, N.F.; WELSH, T. Decentralization of education: why, when, what and how? Paris: UNESCO, 1999.

MOLINA, M.C. A contribuição do PRONERA na construção de políticas públicas de educação do campo e desenvolvimento sustentável. Tese (Doutorado em Desenvolvimento Sustentável) - Programa de Pós-Graduação do Centro de Desenvolvimento Sustentável, Universidade de Brasília, Brasília, 2003.

MOVIMENTO DOS TRABALHADORES RURAIS SEM-TERRA (MST). Manifesto das Educadoras e dos Educadores da Reforma Agrária ao Povo Brasileiro. Brasília: MST, 1997. 
MUNDY, K. Retrospect and prospect: education in a reforming World Bank. International Journal of Educational Development, v. 22, p. 483-508, 2002.

OLIVEIRA, M.B. Inovação e neoliberalismo: a experiência brasileira. In: CALDART, R.; ALENTEJANO, P. (Orgs.). MST, Universidade e Pesquisa. São Paulo: Expressão Popular, 2014. p. 39-59.

ORGANIZAÇÃO DAS NAÇÓES UNIDAS PARA A EDUCAÇÃO, A CIÊNCIA E A CULTURA (UNESCO). Relatório de Monitoramento Global da Educação. Representaçáo da UNESCO no Brasil. Brasília: UNESCO, 2016.

SADER, E. A vingança da História. São Paulo: Boitempo, 2003.

SCHULTZ, T.W. Investment in man: an economist's view. Social Service Review, v. 33, n. 2, p. 109-117, 1959.

SCHUMPETER, J. Teoria do desenvolvimento econômico. São Paulo: Nova Cultural, 1997.

SEGRERA, F.L. América Latina: crisis del posneoliberalismo y ascenso de la nueva derecha. Buenos Aires: CLACSO, 2016.

SGUISSARDI, V. Fórum Social Mundial: um outro mundo é possível. Educação e Sociedade, v. 22, n. 75, ago. 2001. Disponível em: http://www.scielo.br/scielo. php?script=sci arttext\&pid=S0101-73302001000200014.

TYACK, D.; TOBIN, W. The grammar of schooling: Why has it been so hard to change? American Educational Research Journal, v. 31, n. 3, p. 453-479, 1994.

WOODS, N. The globalizers: the IMF, the World Bank, and Their Borrowers. Ithaca, NY: Cornell University Press, 2006.

ZAJDA, J. Introduction. International Review of Education, v. 50, n. 3-4, p. 199-221, 2004.

Recebido em 30 de maio de 2017.

Aceito em 10 de agosto de 2017. 